\title{
Weighted analyses for cohort sampling designs
}

\section{Robert J. Gray}

\section{Erratum to: Lifetime Data Anal (2009) 15:24-40 DOI 10.1007/s10985-008-9095-z}

A factor of $M_{+}^{-1}$ was omitted from formula (3). The correct formula is

$$
M_{+}^{-1}\left(\hat{V}_{Z}+M_{+}^{-1} \sum_{j}\left[\left\{w_{j}(1)-1\right\} D_{j} \hat{V}_{Z j}^{1}+\left\{w_{j}(0)-1\right\}\left(M_{j}-D_{j}\right) \hat{V}_{Z j}^{0}\right]\right)
$$

Also, it should have been noted that Graubard and Korn (2002) give an unbiased version of this estimator and discuss extensions to clustered data.

\section{Reference}

Graubard BI, Korn EL (2002) Inference for superpopulation parameters using sample surveys. Stat Sci 17:73-96

The online version of the original article can be found under doi:10.1007/s10985-008-9095-z.

R. J. Gray $(\varangle)$

Department of Biostatistics and Computational Biology, Dana-Farber Cancer Institute,

44 Binney Street, Boston, MA 02115, USA

e-mail: gray@jimmy.harvard.edu 